\title{
EFFECTIVENESS OF SURGICAL MANAGEMENT OF ANKLE FRACTURES IN ATTAINING THE STABILITY OF ANKLE \\ Ramesh $\mathrm{L}^{1}$, Kiran Kumar $\mathrm{L}^{2}$, Rakesh Chandra $\mathrm{M}^{3}$ \\ ${ }^{1,3}$ Assistant Professor, ${ }^{2}$ Associate Professor, Department of Orthopaedics, Government Medical College \& Hospital, Suryapet, Telangana, India.
}

\section{ABSTRACT}

Introduction: Ankle injuries comprise a major group of lower limb trauma. Many of these injuries can be treated by manipulative reduction and conservative treatment and some of these yield satisfactory results, so present study was undertaken to know the effectiveness of surgical management of ankle fractures. Method: 42 surgically treated displaced fractures are included and studied in detail of age, sex, occupation, type of fracture, mode of injury, type of treatment, Clinical evidence of fracture union, Radiological evidence of fracture union, Relation of talus in the ankle mortise, Range of mobility of the ankle, Residual disability and pain, Ability to walk and time of return to duty and complications were noted. Result: 42 cases were surgically treated, most of the patients were operated on an emergency basis within 24 hours of injury. Based on the mechanism of injury Pronation- External Rotation (30.9\%) and Based on Ao Classification Type B - B2 (53.3\%) were the major type of fractures. In the majority of cases, Malleolar screws type of implants used. In overall the final status of patients is good (ability to walk). Conclusion: Displaced ankle fractures need accurate open reduction and internal fixation and postoperative immobilization for 6 weeks. This will suffice to get good results. Post-operative rigid immobilization and protected weight bearing for 12 weeks is minimal to achieve good union followed by physiotherapy to restore the maximum range of movements

Keywords: Ankle Fractures; Surgical management, Stability; Effectiveness.

\section{INTRODUCTION}

Ankle injuries comprise a major group of lower limb trauma [1]. The importance of ankle joint lies in the fact that the entire body weight is transmitted through it into the foot and locomotion essentially depends upon its stability [2]. Proper understanding of the mechanism and classification of ankle fractures began after their challenging paper by Ashhurst and Bromer [3]. It must be realized that most of these injuries are mixed bony ligamentous failure due to deforming force $[4,5]$.

Many of these injuries can be treated by manipulative reduction and conservative treatment and some of these yield satisfactory results. It is an established fact that in all types of displaced ankle fractures of closed nature, early open reduction and internal fixation gives better anatomical union and early mobilization thus avoiding all the complications of prolonged immobilization [6]

Though household injuries like slipping from staircase, tripping while walking and fall from a height are well known for ankle injuries, there are also many other modes of ankle injuries [7]. Industrial revolution has led to very, fast means of transport and an increase in vehicular accidents, increasing the incidence of ankle injuries.

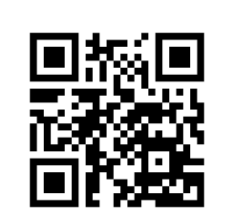

DOI: $10.31878 / \mathrm{ijcbr} .2019 .52 .14$

eISSN: 2395-0471

pISSN: 2521-0394
If we look more closely, we will find that man's increased activities and interests are the main contributory factors for the ankle injuries. Present study of ankle fractures is conducted to assess the outcome of Surgical Management of the ankle fractures.

\section{MATERIAL AND METHODOLOGY}

Study design: An observational descriptive study

Research place: Department of Orthopedics, Sri Venkata Sai Hospital, Mahabubnagar

Ethics approval: Study was approved by the institutional ethics committee and informed consent was obtained from the participants.

Study period: 2 years prospective study

Sample size: Forty-two

Inclusion criteria: Though the total no of cases of injuries around ankle were 52, only the 42 surgically treated displaced fractures are included and studied in detail. Surgical procedure was done by senior orthopaedician.

Exclusion criteria: Rest of cases which were ligamentous injuries and un-displaced fractures, treated by conservative methods are not included.

\section{Methodology:}

The patient's general condition, other associated injuries and routine lab investigation were noted. Pre and postoperative procedure: All Patients were given intramuscular injection of Diclofenac Sodium to relive pain. Intra Venous lines were started in cases of necessity. All

Correspondence: Dr Kiran Kumar, Associate Professor, Department of Orthopaedics, Government Medical College \& Hospital, Suryapet, Telangana. Email: rameshgmesrpt@gmail.com 
those who had open wounds were also given Inj. Tetanus toxoid, $0.5 \mathrm{cc} \mathrm{IM}$, and /or Tetanus immunoglobulins as indicated.

Most of the patients were operated on emergency basis within 24 hours of injury. All cases were operated under spinal anaesthesia and tourniquet control. Standard anteromedial, posteromedial or lateral approaches were used. Postoperatively below knee POP slab was given until the $10^{\text {th }}$ postoperative day, when suture removal was done. Non-weight bearing mobilization of the ankle was done when fixation was found to be stable. Below knee POP cast was applied in cases where fixation was not secure or where lateral malleolus fixation was not contemplated. During this period patients were advised to keep their limbs elevated and perform active toe movements to prevent swelling of the foot and ankle. Below knee cast was removed after 6 weeks and the ankle joint was mobilized. The patients were advised to come for follow up once in 10 days initially for the first month and thereafter monthly until fracture union and good recovery occurred. Patients in whom, the fixation was stable, cast was removed, and the ankle joint was mobilized at the end of the second week.

Parameter studied: Age, sex, occupation, type of fracture, mode of injury, type of treatment, Clinical evidence of fracture union, Radiological evidence of fracture union, Relation of talus in the ankle mortise, Range of mobility of the ankle, Residual disability and pain, Ability to walk and time of return to duty.

\section{RESULTS}

Management: (Conservative Vs Surgical): 10 undisplaced fractures were treated conservatively, 42 cases were surgically treated (study population). Most of the patients were operated on emergency basis within 24 hours of injury.

Table 1: Age, sex wise distribution of patients

\begin{tabular}{l|l}
\hline \multicolumn{1}{c|}{ Age in years } & No. of cases (\%) \\
\hline $10-20$ & $8(20)$ \\
\hline $21-30$ & $6(13.3)$ \\
\hline $31-40$ & $14(33.3)$ \\
\hline $41-50$ & $7(16.67)$ \\
\hline $51-60$ & $4(10)$ \\
\hline $61-70$ & $3(6.67)$ \\
\hline Male & $34(80.9)$ \\
\hline Female & $8(19)$ \\
\hline
\end{tabular}

Table 2: Occupation of patients

\begin{tabular}{l|l}
\hline \multicolumn{1}{c|}{ Category } & N (\%) \\
\hline Agricultural and other labourers & $23(54.76)$ \\
\hline Officials (sedentary job workers) & $7(16.67)$ \\
\hline House wife's & $6(13.33)$ \\
\hline Students & $6(13.33)$ \\
\hline
\end{tabular}

Table 3: Types of fracture

\begin{tabular}{l|l}
\hline \multicolumn{1}{c|}{ Mechanism of injury } & N (\%) \\
\hline \multicolumn{2}{l}{ (Based on Lauge - Hansen's system) } \\
\hline Supination - Adduction & $9(21.4)$ \\
\hline Supination - External rotation & $11(26.2)$ \\
\hline Pronation - Abduction & $7(16.67)$ \\
\hline Pronation - External Rotation & $13(30.9)$ \\
\hline Pronation - Dorsiflexion & $1(2.38)$ \\
\hline
\end{tabular}

Based on Ao Classification

\begin{tabular}{l|c}
\hline Type A - A2 & $9(21.4)$ \\
\hline Type B - B2 & $22(53.3)$ \\
\hline Type C - C2 & $(26.7)$ \\
\hline
\end{tabular}

Table 4: Mode of Injury

\begin{tabular}{l|c}
\hline Cause of Injury & No. of Cases \\
\hline Fall from height & $1(3.33)$ \\
\hline Road traffic accidents & $25(57)$ \\
\hline Domestic Accidents & $8(20)$ \\
\hline Sports & $4(10)$ \\
\hline Assault & $1(3.3)$ \\
\hline Slip on stairs & $(6.67)$ \\
\hline
\end{tabular}

Table 5: Implants used

\begin{tabular}{l|l}
\hline Surgical implants used & No. of cases (\%) \\
\hline Malleolar screws & $20(47.61)$ \\
\hline Plating & $9(20.67)$ \\
\hline Rush nails & $8(20)$ \\
\hline K wires & $3(6)$ \\
\hline Tension band wire & $2(4.76)$ \\
\hline
\end{tabular}

Among the ankle injuries Potts fractures (Potts fractures) of the ankle form a moderate number of fractures seen in our hospital. They are common injuries during the prime life and cause disability and loss of man power if not treated properly. In general, they are unstable and some of them especially medial malleolus may go for non - union due to soft tissue interposition requiring a second surgical procedure.

Clinical evidence of fracture healing: In the study there was definitive evidence of union in 30 cases, 6 cases of malunion, at the end of 12 weeks.

Radiological evidence of union of fracture: In this study there were 24 cases of radiological union at the end of 12 weeks.

Relation of the talus in the ankle mortise: In this study there were 5 cases of talar tilt, 3 cases of injury to 
tibial plafond, 5 cases of talar shift with medial clear space more than $4 \mathrm{~mm}$.

Range of mobility of the ankle: After removing casting / slab when there was definite evidence of clinical and radiological evidence of union, active exercise and physiotherapy advised and range of movements examined.

Table 6: Range of mobility

\begin{tabular}{l|l|l}
\hline Dorsiflexion & Plantarflexion & No. of Cases \\
\hline $25^{0}$ & $60^{0}$ & 0 \\
\hline $20^{0}$ & $45^{0}-50^{0}$ & $28(66.66)$ \\
\hline $15^{0}-20^{0}$ & $35^{0}-40^{0}$ & $11(26.66)$ \\
\hline $10^{0}-15^{0}$ & $25^{0}-35^{0}$ & $(7.14)$ \\
\hline
\end{tabular}

Table 7: Residual disability pain

\begin{tabular}{l|l}
\hline Pain status & No of cases \\
\hline No pain; normal ankle & $26(61.9)$ \\
\hline $\begin{array}{l}\text { Minimal pain after walking long } \\
\text { distance or running }\end{array}$ & $13(30.95)$ \\
\hline $\begin{array}{l}\text { Residual pain associated with } \\
\text { swelling and limp moderately inca- } \\
\text { pacitating }\end{array}$ & $3(7.14)$ \\
\hline
\end{tabular}

Table 8: Final status of patients (Ability to walk and time of return to duty)

\begin{tabular}{l|l}
\hline Ability to walk & No. of cases \\
\hline Good & $31(73.3)$ \\
\hline Fair & $8(20)$ \\
\hline poor & $3(6.67)$ \\
\hline
\end{tabular}

Table 9: Complications

\begin{tabular}{l|l}
\hline Complications & No. of cases (\%) \\
\hline Residual pain & $4(10)$ \\
\hline Infection & $1(3.33)$ \\
\hline Implant exposed & $1(3.33)$ \\
\hline Arthritis & $1(3.33)$ \\
\hline
\end{tabular}

Good: No displacement

Fair: Slow consolidation of fracture, anterior, Posterior or distal displacement of medial malleolar fragment of $2 \mathrm{~mm}$ up to $5 \mathrm{~mm}$ Displacement of lateral malleolar fragment, $+1.5^{0}+2.5^{0}$ of tilt of talus. Minimal or questionable joint damage noted on $\mathrm{x}$ ray or at the time of surgery. Pain is moderately incapacitating - mild analgesics are required. Walking is restricted; Partial subsidence of pain with physiotherapy and short-wave diathermy. Patient may return to work but may require arthrodesis after few years or must shift to less stressful job.

Poor: Clinical evidence of pain at fracture site and deformity. Radiological evidence of malunion, ankle movements $50 \%$ or less and pain is constant and unable to walk, requires arthrodesis.

\section{DISCUSSION}

Initial history and clinical assessment \{fracturedislocation, gross deformity and the condition of soft tissues (swelling, closed or open fracture, swelling) tenderness, severity of pain $\}$ are helpful [8].
It is noted by many authors, when discussing the relationship between the reduction and clinical outcome, adequacy of reduction alone doesn't determine the result, other factors like type of fracture; amount of displacement of talus, tear of deltoid ligament etc. should also be considered. Hence each case is evaluated separately by taking the following into consideration at the end of 12 weeks [9-11].

All displaced fractures were treated surgically with open reduction and internal fixation. Malleolar screw was most commonly used for fixation of medial malleolus in our study. Lateral malleolus was fixed with $1 / 3$ tubular plate or rush nails. Another method used for fixation was Tension Band Wiring.

A study by Wang et al, concluded that effective method to treat ankle fracture with deltoid ligament injury by open reduction and internal fixation of ankle fracture and repair of the deltoid ligament injury, which can effectively rebuild medial instability and has satisfactory effectiveness [12].

There is a significant increase in intra-articular contact stresses even with minimal residual displacement of the talus, leading to degenerative changes of the joint. The initial management of all ankle fractures involves immobilization in a splint - after reduction, if there is dislocation. Further decisions regarding definitive treatment, either conservative or surgical, depend on the stability of the fracture [13].

Accurate reduction and fixation of the malleolar fractures is emphasized, because even the slightest incongruity leads to arthritis and instability of ankle mortise affecting the weight bearing and locomotion of the patient $[11,14]$.

Open reduction and internal fixation for bimalleolar and tri malleolar fractures with early mobilization given good results [15].

\section{CONCLUSION}

In conclusion that all displaced ankle fractures need accurate open reduction and internal fixation and postoperative immobilization for 6 weeks. This will suffice to get good results. Post-operative rigid immobilization and protected weight bearing for 12 weeks is minimal to achieve good union followed by physiotherapy to restore the maximum range of movements. It is also evident from malunion in 4 cases, that interposed soft tissue should be excised before fixing the fracture

Suggestions: Attention paid to tensionless suturing techniques and careful handling of skin resulted in excellent wound healing.

\section{REFERENCES}

[1] Claire L. Brockett, Graham J. Chapman. Biomechanics of the ankle. Orthop Trauma. 2016;30(3): 232-8.

[2] Tung-WuLu, Chu-Fen Chang Biomechanics of human movement and its clinical applications. The Kaohsiung Journal of Medical Sciences. 2012;28 $(2 \mathrm{~s}): 13-25$.

[3] Dr Kishore. Functional outcome of treatment of bimallolar fractures. Dissertation submitted to 
university of Seychelles American Institute of Medicine. Available online http://www.mchorth.com/pdf/Dr.kishor\%20margani.pdf.

[4] Frank C, Wilson Jr, Arne L Skilberd MB. Long term results in the treatment of displaced bimalleolar fractures. JBS.1966;48(A6):1065-78

[5] Jergesen P. Open reduction of fractures and dislocations of ankle American Journal of Surgery. 1959;98:136

[6] Charley J. Fractures of ankle. The closed treatment of common fractures. $1961 ; 3^{\text {rd }}$ edition.

[7] Ankle Injuries: Causes and Treatments. Available from : https://www.webmd.com/fitness-exercise/ guide/ankle-injuries-causes-and-treatments\#1

[8] Vasileios Lampridis, Nikolaos Gougoulias, Anthony Sakellariou. Stability in ankle fractures Diagnosis and treatment. EFORT Open Rev. 2018 May; 3(5): 294-303.

[9] Ramsamy RR, Sherry P. Role of a fibular nail in the management of Weber type $B$ ankle fractures in elderly patients with osteoporotic bone. Injury. $2001 ; 32(6) ; 477-85$

[10] Internal fixation And Early Mobilization in ankle fracture. Indian journal of Orthopaedics. 1999;33 (4):256-9

[11] Savage TJ, Garry MC, Stonepa JJ. The internal fixation of ankle fracture repair. Clinical podiatr med surgery. 1995;12(4):603-33

[12] Wang H, Gu Z, Liu Y, Xu J, Jan J, Zhang J, Peng C. Effectiveness of surgery in treatment of ankle fractures associated with deltoid ligament injury. Zhongguo Xiu $\mathrm{Fu}$ Chong Jian Wai Ke $\mathrm{Za}$ Zhi. 2015;29(4):416-9.

[13] Anderson DD, Goldsworthy JK, Kiran Shivanna, Grosland NM, Pedersen DR, Thomas TP et al. Intra-articular Contact Stress Distributions at the Ankle throughout Stance Phase - Patient-Specific Finite Element Analysis as a Metric of Degeneration Propensity. Biomech Model Mechanobiol. 2006; 5(2-3): 82-9.

[14] Srinivasan CM, Moran CG. Internal fixation of ankle fractures in the very elderly. Injury. 2001:32 (7S): $559-63$.

[15] Kumar P, Mehrota A, Srivastava N. Internal Fixation and Early Mobilization In Displaced Ankle Fracture. Indian journal of Orthopedics in year 1999;33(4): 256-9. 